\title{
UTILIZAÇÃO DE ABRAÇADEIRAS DE NÁILON 6.6 (POLIAMIDA) COMO MÉTODO DE LIGADURA PARA ORQUIECTOMIA DE CAMPO EM BOVINOS
}

\author{
Valmir Fernandes \\ Monique Catarine Fischer Possamai ${ }^{2}$ \\ Rafael Santos Tramontin ${ }^{2}$ \\ Salviano Tramontin Belettini ${ }^{3}$ \\ Max Gimenes Ribeiro ${ }^{4}$ \\ Juliano Bortolo De Conti ${ }^{4}$ \\ José Ricardo Pachaly
}

FERNANDES, V.; POSSAMAI, M. C. F.; TRAMONTIN, R. S.; BELETTINI, S. T.; RIBEIRO, M. G.; DE CONTI, J. B.; PACHALY, J. R. Utilização de abraçadeiras de náilon 6.6 (poliamida) como método de ligadura para orquiectomia de campo em bovinos. Arq. Ciênc. Vet. Zool. UNIPAR, Umuarama, v. 19, n. 1, p. 29-33, jan./mar. 2016.

RESUMO: Este artigo apresenta e discute os resultados de um estudo sobre a orquiectomia eletiva realizada em campo pela técnica aberta, na Região Noroeste do Estado do Paraná, em 880 bovinos, utilizando abraçadeira de náilon 6.6 (poliamida) para ligaduras vasculares hemostáticas. Os animais responderam bem a cirurgia realizada sob contenção física em tronco de contenção, com anestesia local intratesticular, sem quaisquer problemas operatórios. A única complicação observada foi a ocorrência de miíases em 25 animais (3,09\%). O método empregado teve fácil execução e baixo custo, sendo plenamente efetivo na substituição do fio de náilon cirúrgico para promover hemostasia preventiva, com redução do tempo cirúrgico. Os resultados permitem sugerir o uso de abraçadeiras de náilon 6.6 (poliamida) para as ligaduras vasculares emorquiectomias realizadas em campo nos bovinos, como método seguro e eficiente, capaz de reduzir o tempo de procedimento cirúrgico.

PALAVRAS-CHAVE: Castração de machos. Cirurgia. Ligadura.

\section{USE OF 6.6 NYLON (POLYAMIDE) CABLE TIES AS A METHOD FOR MASSIVE VASCULAR LIGATURE IN BOVINE FIELD ORCHIECTOMY}

\begin{abstract}
This paper reports the results of a study about elective field orchiectomy performed by open technique, in the northwestern region of Paraná State, Brazil, in 880 bulls, using 6.6 nylon (polyamide) cable ties for hemostatic vascular ligature. The cattle responded well to surgery performed under physical restraint and intra-testicular local anesthesia, without any surgical intercurrence. The only complication was the occurrence of myiases in 25 animals $(3.09 \%)$. The method was inexpensive and easy to perform, being fully effective in replacing nylon sutures to promote preventive surgical hemostasis, and significantly reducing surgical time. These results indicate the use of 6.6 nylon (polyamide) cable ties for hemostatic vascular ligatures in field orchiectomyin bovine cattle, as a safe and efficient method, capable to reduce surgical time.
\end{abstract}

KEYWORDS: Ligature. Male castration. Surgery.

\section{EMPLEO DE ABRAZADERAS DE NYLON 6.6 (POLIAMIDA) COMO MÉTODO DE LIGADURA PARA CASTRACIÓN DE CAMPO EN BOVINOS}

RESUMEN: Este artículo presenta y discute los resultados de un estudio sobre la castración electiva realizada en campo por la técnica abierta, en la Región Noroeste del Estado de Paraná, en 880 bovinos, empleando abrazadera de nylon 6.6 (poliamida) para ligaduras vasculares . Los animales respondieron bien a la cirugía realizada bajo sujeción física y anestesia local intratesticular, sin cualquier problema quirúrgico. La única complicación observada fue la aparición de miíasis en 25 animales (3,09\%). El método empleado ha sido de fácil ejecución y bajo costo, siendo plenamente eficaz en la sustitución del hilo de nylon quirúrgico para promover la hemostasia preventiva, con reducción del tiempo quirúrgico. Los resultados sugieren el empleo de abrazaderas de nylon 6.6 (poliamida) para ligaduras vasculares en castraciones de bovinos realizadas en campo, como método seguro y eficiente, capaz de reducir el tiempo del procedimiento quirúrgico.

PALABRAS CLAVE: Castración de machos. Cirugía. Ligadura.

DOI: https://doi.org/10.25110/arqvet.v19i1.2016.5787

${ }^{1}$ Médico Veterinário, Mestre pelo Programa de Pós-Graduação em Ciência Animal da Universidade Paranaense - UNIPAR. Praça Mascarenhas de Moraes, 4282, Centro, Umuarama, Paraná, CEP 87502-100, Brasil. veteagro@hotmail.com

${ }^{2}$ Médica(o) Veterinária (o), discente do Programa de Pós-Graduação em Ciência Animal da Universidade Paranaense - UNIPAR, bolsista PROSUP/CAPES. ${ }^{3}$ Médico Veterinário, Mestre pelo Programa de Pós-Graduação em Ciência Animal da Universidade Paranaense - UNIPAR. Diretor do Hospital Veterinário da Universidade Paranaense - UNIPAR.

${ }^{4}$ Médico Veterinário, Mestre, Doutor. Docente do Curso de Medicina Veterinária da Universidade Estadual de Maringá - UEM.

${ }^{5}$ Médico Veterinário, Mestre, Doutor, Pós-Doutor. Professor Orientador do Programa de Pós-Graduação em Ciência Animal da Universidade Paranaense UNIPAR, Umuarama, PR, Brasil. Diretor Científico do Instituto Brasileiro de Espeialidades em Medicina Veterinária - ESPECIALVET, Maringá, PR, Brasil 


\section{Introdução}

A orquiectomia é uma prática tradicionalmente empregada em diversos modelos de criação de bovinos e equídeos, pois os machos castrados se tornam mais dóceis, e no caso dos bovinos observa-se um incremento no ganho de peso (SILVA et al., 2009; FINGER et al., 2011). A castração é prática comum e usual na bovinocultura de corte, e tem como objetivo obter animais mais dóceis, promovendo manejo mais fácil, preservação das instalações e pastagens, menor incidência de problemas nos cascos e ausência de montas indesejadas. Bovinos castrados produzem carne de maior qualidade, com melhor deposição de gordura e maior marmorização, sendo menor o risco de desenvolvimento de cortes DFD (dark, firm, dry) (ROÇA et al., 2011).

Apesar de ser um procedimento de fácil execução, a taxa de problemas associados é relativamente elevada, sendo que 20 a 38\% dos cavalos apresentam algum tipo de complicação (SILVA et al., 2009; FINGER et al., 2011). A remoção de testículos em posição fisiológica pode ser realizada empregando três técnicas: aberta, fechada ou semifechada, e tradicionalmente a incisão escrotal é deixada aberta para cicatrizar por segunda intenção (BAILEY, 2004).

A orquiectomia realizada pela técnica aberta, com remoção da túnica parietal, permite que o cordão espermático seja visualizado mais claramente, facilitando a hemostasia (SILVA et al., 2006). Nessa técnica, são realizadas duas incisões envolvendo a pele do escroto, a túnica dartos, a fáscia escrotal e o folheto parietal da túnica vaginal. As incisões geralmente têm de 8,0 a $10,0 \mathrm{~cm}$ de comprimento, dependendo do tamanho dos testículos, e são feitas de cada lado da rafe mediana, a cerca 2,0 cm da mesma. Os testículos são empurrados para fora do folheto parietal da túnica vaginal, ao qual permanecem presos pelo ligamento da cauda do epidídimo. A seguir, esse ligamento é seccionado para libertar a túnica vaginal e o músculo cremaster, expondo os vasos sanguíneos do plexo pampiniforme e o ducto deferente, que podem então ser ligados (STAINKI, 2006; ALMEIDA et al., 2010).

Na técnica fechada são realizadas duas incisões semelhantes às praticadas na técnica aberta, porém sem seccionar o folheto parietal da túnica vaginal. O testículo é segurado com firmeza e a fáscia que envolve a túnica vaginal é separada desta até que o músculo espermático e a túnica vaginal estejam claramente expostos, permitindo que o funículo espermático seja ligado e seccionado (SEARLE et al. 1999).

Quanto à técnica semi-fechada, a abordagem é semelhante à da técnica fechada, sendo que após incisão cutânea se faz exposição do músculo cremaster e do folheto parietal da túnica vaginal, seguida por localização, exteriorização e ligadura do plexo pampiniforme (SEARLE et al. 1999).

Segundo Silva et al. (2009), na escolha do procedimento cirúrgico a ser empregado recomenda-se atentar ao desejo do proprietário, ao método de contenção, às condições ambientais e aos possíveis problemas e complicações. Será considerado melhor o procedimento que causar menos estresse e menos intercorrências pós-operatórias, resultando em recuperação mais rápida em todas as espécies, e maior ganho de peso nos animais de corte.

A identificação pré-operatória dos fatores de risco para o desenvolvimento de complicações pode garantir que sejam tomadas medidas adequadas para reduzir esses riscos, ajudando a evitar algumas complicações. Quando ocorrem complicações, devem ser identificadas prontamente, para rápida tomada de providências terapêuticas (GETMAN, 2009).

Silva et al. (2009), estudando o comportamento de feridas cirúrgica após orquiectomia em bovinos nas diferentes estações do ano, encontraram como principais complicações as miíases, seguidas por abscessos, funiculite e granulomas, em ordem decrescente de importância.

$\mathrm{Na}$ orquiectomia realizada em bovinos, os métodos de contenção física incluem o uso de bretes e a imobilização em decúbito lateral (SILVA et al., 2009), e existem diversas indicações e técnicas de anestesia local (MASSONE, 2003).

Segundo Tranquili e Skarda (2013), a cirurgia pode ser realizada por meio de contenção farmacológica e/ou por anestesia regional, tanto em posição quadrupedal quanto em decúbito, ou sob anestesia geral intravenosa. A anestesia regional pode ser induzida pela injeção intratesticular de anestésico local, e não provoca efeitos que prejudiquem o consumo da carne dos animais. Para a anestesia regional, o anestésico é injetado na linha de incisão sob o tecido subcutâneo, infiltrando-se 3 a $5 \mathrm{~mL}$ de cloridrato de lidocaína a $2 \%$, e por via intratesticular infiltra-se volume de 10 a 15 $\mathrm{mL}$ em cada testículo, para cada $200 \mathrm{~kg}$ de massa corporal. $\mathrm{O}$ anestésico é absorvido rapidamente pelos vasos linfáticos e insensibiliza as fibras sensoriais no cordão espermático. De modo geral, o uso racional do cloridrato de lidocaína a $2 \%$ possui baixo custo e proporciona boa analgesia intraoperatória, recuperação rápida e mínimos efeitos adversos.

As complicações que podem ocorrer após orquiectomias incluem hemorragias, edemaescrotal, infecção incisional, peritonite, trauma peniano, bem como eventração, nos casos de protrusão visceral por meio do canal inguinal (FINGER et al., 2011). Desse modo, a utilização de métodos preventivos de hemostasia é fundamental (SILVA et al., 2006).

A abraçadeira de náilon 6.6 (poliamida) tem sido empregada para substituir o fio de náilon em diversas intervenções cirúrgicas em animais, visando à hemostasia preventiva. É um dispositivo resistente à tração, que apresenta um eficiente sistema de trava. É de fácil aquisição, manuseio e esterilização, com baixo custo e boa tolerância pelo organismo (SILVA et al., 2006; BARROS et al., 2009; SILVA et al., 2009; FINGER et al., 2011; SANTOS et al. 2012).

As abraçadeiras de náilon 6.6 (poliamida) são dispositivos de uso corrente na atualidade, fabricadas no mundo inteiro por diversas empresas, com finalidade de prender e organizar a distribuição de fios e cabos em equipamentos eletroeletrônicos. Estão disponíveis no mercado em diversas cores e tamanhos, sendo identificadas por uma sequência de letras e números que fornecem informações sobre o tipo, a resistência tênsil, o comprimento da fita, a cor, o material, e a quantidade de unidades por embalagem e o tipo de embalagem. No Brasil, em nível de varejo, as abraçadeiras são identificadas apenas pelas suas dimensões, expressas em milímetros. Com relação à resistência ao calor, as abraçadeiras de náilon 6.6 (poliamida) suportam temperaturas de até $260^{\circ} \mathrm{C}$. Apresentam ainda alta resistência à tração, que é de $8,0 \mathrm{~kg}$ para a abraçadeira de $2,5 \times 100 \mathrm{~mm}$, em seu estado natural, e de cerca de 9,0 kg para a mesma abraçadeira, quando autoclavada (BARROS et al., 2009). 
Santos et al. (2012) empregaram o método em cães adultos, concluindo que seu uso é mais prático e seguro que o de fio de náilon cirúrgico nas ligaduras em deferentectomias, e equivalente em orquiectomias. Os autores ainda mencionam que o tempo de cirurgia é menor com o uso da abraçadeira de náilon 6.6 (poliamida) em comparação com o fio de náilon cirúrgico, e que o sistema de trava da abraçadeira serve para identificar, por palpação, os animais que foram submetidos às cirurgias com o dispositivo. Mattos (2007) comparou a reação tecidual produzida pela abraçadeira de náilon 6.6 (poliamida) e pelo fio de náilon cirúrgico por meio da análise histopatológica em ratas Wistar, concluindo que não existe diferença significativa entre os métodos. Barros et al. (2009) avaliaram o uso de abraçadeiras de náilon 6.6 (poliamida) em ovário-histerectomia de cadelas, como método de ligadura vascular de pedículos ovarianos e cotos uterinos, considerando os parâmetros tempo cirúrgico, custo, segurança e biocompatibilidade. Os autores concluíram que o método é seguro, eficiente, rápido e de baixo custo. Neves et al. (2004) compararam duas técnicas de orquiectomia em cavalos, utilizando emasculador e abraçadeira de náilon 6.6 (poliamida), empregadas por alunos de graduação em Medicina Veterinária, sob a supervisão docente. Ambas as técnicas se mostraram viáveis e de fácil aplicabilidade na prática de ensino, sendo que o uso do emasculador induziu maior incidência de hemorragia, em comparação à hemostasia com as abraçadeiras. Silva et al. (2006) estudaram a eficácia da abraçadeira de náilon 6.6 (poliamida) como método hemostático na orquiectomia em equinos, avaliando possíveis complicações pós-operatórias e custo do procedimento. Segundo os autores, a abraçadeira de náilon 6.6 (poliamida) mostrou-se resistente à tração exercida no local da aplicação, e quando comparada ao uso do emasculador e categute, apresentou menor custo e reduziu o tempo de duração do procedimento. Silva et al. (2009), trabalhando com 168 bovinos machos com 18 meses de idade e peso médio de $290 \mathrm{~kg}$, verificaram complicações pós-operatórias e evolução clínica da cicatrização três, 23, 43 e 63 após o procedimento. As técnicas cirúrgicas não influenciaram na ocorrência de complicações, e a abraçadeira de náilon 6.6 (poliamida) mostrou-se eficiente na hemostasia preventiva. Fingeret al. (2011) compararam duas técnicas de hemostasia aplicadas por estudantes de medicina veterinária sem experiência na orquiectomia em equinos, concluindo que as abraçadeiras de náilon 6.6 (poliamida) apresentam a mesma viabilidade que o emasculador, e que ambas as técnicas tem fácil aplicabilidade.

Este artigo apresenta e discute os resultados de um estudo sobre o uso de abraçadeiras de náilon 6.6 (poliamida) para ligadura vascular na orquiectomia eletiva de campo em 880 bovinos (Bos sp.).

\section{Material e Métodos}

Foram submetidos a orquiectomia 880 bovinos (Bos sp.) com massa corporal de 295 a $405(345,21 \pm 31,24) \mathrm{kg}$, empregando-se abraçadeiras de náilon 6.6 (poliamida) para as ligaduras. Os procedimentos foram realizados na Região Noroeste do Estado do Paraná, abrangendo propriedades rurais nos municípios de Alto Paraíso, Alto Piquiri, Douradina, Maria Helena, Umuarama e Xambrê, e também o Hospital
Veterinário da Universidade Paranaense (HV-UNIPAR, município de Umuarama).

Em todos os casos, as orquiectomias foram realizadas como procedimento rotineiro de manejo nas propriedades rurais onde eram mantidos os animais, mediante solicitação desse serviço veterinário por parte de seus proprietários. O projeto referente a este estudo foi registrado no Instituto de Pesquisa, Estudos e Ambiência Científica da Universidade Paranaense - IPEAC/UNIPAR, e aprovado pelo Comitê de Ética em Pesquisa Envolvendo Experimentação Animal da Universidade Paranaense - CEPEEA/UNIPAR, com número de registro geral 27333.

Os touros não passaram por jejum e não foram submetidos a contenção farmacológica antes da realização da orquiectomia. Previamente ao procedimento cirúrgico, cada animal era contido fisicamente em tronco de contenção apropriado, e a bolsa escrotal era lavada com água e sabão e enxaguada com água. Depois disso se realizava antissepsia com solução de iodóforo ${ }^{1}$ a $2,25 \%$ diluída a 1:20, seguida de anestesia local empregando lidocaína ${ }^{2}$ a 2,0\% sem vasoconstritor. A dose de lidocaína para cada testículo variava de 3,0 a 5,0 mL (60 a $100 \mathrm{mg}$ ), sendo 0,5 mL (10 mg) administrados por via intradérmica, na linha de incisão, e o restante administrado por via intratesticular.

Neste estudo, as orquiectomias foram realizadas por diversos cirurgiões, desde profissionais até estudantes de graduação em treinamento, devidamente supervisionados por profissionais. O procedimento cirúrgico foi realizado pela técnica aberta proposta por Turner e McIlwaith (2002), em que após a anestesia local cada testículo é exteriorizado através de incisões cutâneas individuais (Figura1A), removendo-se testículo, epidídimo, túnica dartos, fáscias escrotais e túnica vaginal parietal, mantendo-se na bolsa escrotal a túnica vaginal parietal e o músculo cremaster. Uma vez exteriorizado o testículo (Figura 1B) e expostos os elementos anatômicos, uma abraçadeira de náilon 6.6 (poliamida) da medida 3,6 x 250,0 mm, previamente autoclavada, era aplicada no funículo espermático na posição mais proximal possível, realizando sua ligadura (Figura 1C).

$\mathrm{O}$ restante da abraçadeira era cortado rente à área de fechamento empregando-se um alicate para corte de unhas de cães previamente esterilizado (Figura 1D). Esse instrumento foi escolhido para isso após diversos testes, e provou ser mais eficiente que tesouras ou outros tipos de alicate.

A seguir, mediante incisão abaixo da ligadura, o testículo e demais estruturas eram removidos da bolsa escrotal, que não era suturada, mantendo-se aberta para drenagem e cicatrização por segunda intenção.

Finalizado o procedimento cirúrgico, a área operada era inspecionada para verificar a segurança das ligaduras e a ausência de hemorragias, e novamente lavada com a mesma solução de iodóforo, aplicando-se a seguir sobre as feridas cirúrgicas um medicamento com ação repelente.

Os bovinos castrados não receberam antibióticos ou antiinflamatórios, mas somente uma dose de $0,2 \mathrm{mg} / \mathrm{kg}$ de doramectina $^{3}$, por via subcutânea, como endo e ectoparasiticida.

\footnotetext{
${ }^{1}$ Biofor ${ }^{\circledR}$, Lab. Chemitec, São Paulo - SP.

${ }^{2}$ Lidovet $\AA$, Lab. Bravet, Rio de Janeiro - RJ

${ }^{3}$ Dectomax ${ }^{\circledR}$, Lab. Pfizer/Zoetis, São Paulo - SP.
} 
Os responsáveis pelos animais foram orientados a observá-los com cuidado, comunicando imediatamente quaisquer alterações como hemorragias, tumefações e dificuldade de locomoção nos primeiros dias após as intervenções.

Com vistas à identificação de eventuais problemas iniciais etardios, todos os bovinos foram observados diariamente na rotina das fazendas, onde eram submetidos a sistema de engorda a pasto, recebendo dieta balanceada e sendo pesados a cada trinta dias. Do total de 808 animais, $138(17,08 \%)$ foram examinados aos 30, 60 e 90 dias após a orquiectomia, mediante exame físico e inspeção e palpação da bolsa escrotal.

Figura 1: Imagens fotográficas da realização de orquiectomia em um macho bovino adulto, sob contenção física em tronco e anestesia local intratesticular, empregando como método de ligadura uma abraçadeira de náilon 6.6 (poliamida) da medida 3,6 x 250,0 mm, previamente autoclavada. A. Incisão cutânea individual sobre um testículo, com bisturi; B. Exposição do testículo e demais elementos anatômicos através da incisão; C. Aplicação e fechamento por tração da abraçadeira, para ligadura do funículo espermático na posição mais proximal possível; D. Corte do restante da abraçadeira após a ligadura, empregando um alicate para corte de unhas de cães previamente autoclavado.
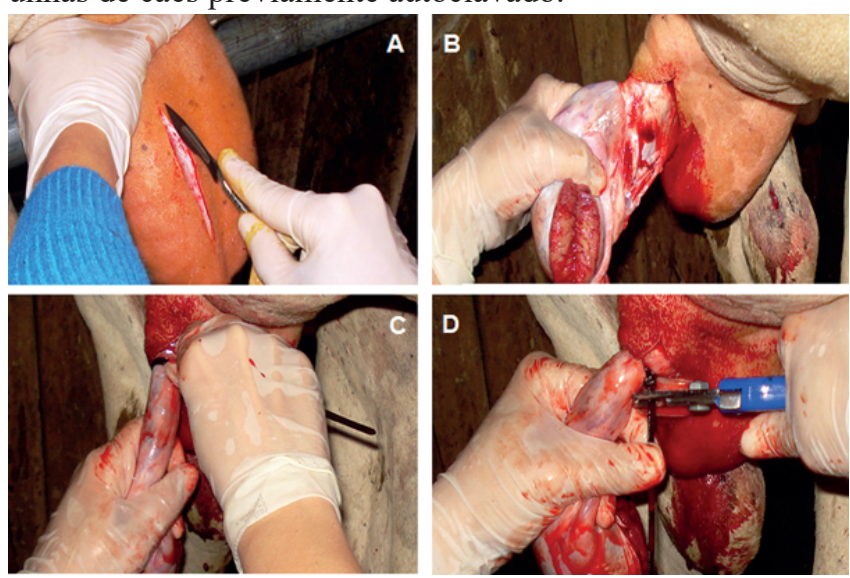

\section{Resultados e Discussão}

Neste estudo foram avaliados os resultados do emprego de abraçadeiras de náilon 6.6 (poliamida) na orquiectomia eletiva de 880 touros realizada pela técnica aberta, conforme indicado por Turner e McIlwaith (2002). Para todos os animais, o tempo para realização do procedimento foi de cinco a 10 minutos, incluindo preparo, antissepsia, administração de medicamentos e ato cirúrgico.

A anestesia local intratesticular foi eficiente para realização dos procedimentos, mesmo empregando dose bem mais baixa que a mencionada na literatura. Neste estudo, a dose de lidocaína para cada testículo variava de 3,0 a 5,0 mL (60 a $100 \mathrm{mg})$, sendo $0,5 \mathrm{~mL}$ (10 mg) administrados por via intradérmica, na linha de incisão, e o restante administrado por via intratesticular. Entretanto, Tranquili e Skarda (2013) indicam volumes muito maiores de 10 a $15 \mathrm{~mL}$ para cada 200 $\mathrm{kg}$ de massa corporal.

O uso das abraçadeiras de náilon 6.6 (poliamida) para a realização da orquiectomia mostrou-se de fácil exe- cução, substituindo adequadamente o fio de náilon cirúrgico no procedimento de ligadura hemostática, em conformidade com os dados publicados por Silva et al. (2006), Barros et al. (2009), Silva et al. (2009), Finger et al. (2011) e Santos et al. (2012).

Ao se exteriorizar o testículo se realizava a separação da túnica vaginal e parietal da cauda do epidídimo. O epidídimo era então tracionado, expondo o funículo espermático para ser ligado em posição proximal com uma única abraçadeira, permitindo a incisão e em seguida a retirada do testículo. Uma vez que cabeça, corpo e cauda do epidídimo se mantinham intimamente inseridos ao testículo, eram removidos conjuntamente, conforme indicado por Almeida et al. (2010).

Os 880 bovinos responderam satisfatoriamente à cirurgia realizada sob contenção física em tronco de contenção, com anestesia local intratesticular, e a única complicação digna de nota foi a ocorrência de miĺases em 25 animais $(3,09 \%)$.

\section{Conclusões}

A orquiectomia realizada em campo pela técnica aberta, para 880 bovinos, utilizando abraçadeira de náilon 6.6 (poliamida) para ligaduras hemostáticas, teve fácil execução e baixo custo, e o dispositivo foi plenamente efetivo na substituição do fio de náilon cirúrgico, promovendo a hemostasia preventiva, sem quaisquer complicações operatórias e tempo cirúrgico curto.

Neste estudo não foi observado nenhum tipo de complicação cirúrgica, indicando o uso de abraçadeiras de náilon 6.6 (poliamida) para as ligaduras vasculares em orquiectomias realizadas em campo nos 880 bovinos, como método seguro e eficiente, capaz ainda de reduzir o tempo de procedimento cirúrgico.

\section{Agradecimentos}

À Diretoria Executiva de Gestão de Pesquisa e Pós-Graduação da Universidade Paranaense (DEGPP - UNIPAR), pela concessão de auxílio financeiro e bolsa de mestrado do Programa Institucional de Treinamento Docente e Técnico-científico (PIT).

\section{Referências}

ALMEIDA, K. B. et al. Orquiectomia em bovinos. Enciclopédia Biosfera, v. 6, n. 9, p. 1-13, 2010.

BAILEY, J. et al. Routine castration in 568 draught colts: incidence of evisceration and omental herniation. Equine Veterinary Journal, v. 36, n. 4, p. 336-340, 2004.

BARROS, B. J. et al. Utilização de abraçadeiras de náilon 6.6 (poliamida) como método de ligadura de pedículos ovarianos e coto uterino em ovário-histerectomia eletiva em cadelas (Canis familiaris). Arquivos de Ciências Veterinárias e Zoologia da UNIPAR, v. 12, n. 1, p. 47-60, 2009.

FINGER, M. A. et al. Comparação de duas técnicas de 
orquiectomia em equinos, empregadas no ensino da técnica cirúrgica veterinária. Archives of Veterinary Science, v. 13, p. 53-59, 2011.

GETMAN, L. M. Review of castration complications: strategies for treatment in the field. Surgery, v. 55, p. 374378, 2009.

MASSONE, F. Anestesiologia veterinária. 4. ed. Rio de Janeiro: Guanabara Koogan, 2003. 326 p.

MATTOS, W. P. Estudo comparativo das reações teciduais produzidas pela abraçadeira de náilon e o fio de náilon cirúrgico implantados na musculatura de ratas. 2007. Disponível em: <http://www.cirurgia.vet.ufba. br/uploads /2008/09/13wellington2007abracadeiraenylon. pdf $>$. Acesso em: 11 maio 2014.

NEVES, T. B. et al. Uso da braçadeira de nylon e emasculador na técnica aberta de castração de equinos. 2004. Disponível em: <http://www.vet.ufmg.br/reprodução/ documentos $>$. Acesso em: 11 maio 2014.

ROÇA, R. O. et al. Imunocastração de bovinos criados em pasto: perfil de ácidos graxos da carne. Disponível em: <http://www.bopriva.com.br/2011_CONBRAVET_ verso198.pdf $>$. Acesso em: 11 maio 2014.

SANTOS, I. F. C. et al. Eficácia da abraçadeira e do fio de náilon na diferentectomia e laqueação dos ductos deferentes em cães adultos (estudo comparativo). Ars Veterinaria, v. 28 , n. 2, p. 75-84, 2012.

SEARLE, D. et al. Equine castration: review of anatomy, approaches, techniques and complications in normal, cryptorchid and monorchid horses. Australian Veterinary Journal, v. 77, n. 7, p. 428-434, 1999.

SILVA, L. A. F. et al. Emprego da abraçadeira de náilon na orquiectomia em equinos. Acta ScientiaeVeterinariae, v. 34, p. 261-266, 2006.

SILVA, L. A. F. et al. Orquiectomia em bovinos empregando abraçadeira de náilon na hemostasia preventiva: efeito da estação do ano, método de contenção e técnica cirúrgica. Ciência Animal Brasileira, v. 10, n. 1, p. 261-270, 2009.

STAINKI, D. R. Orquiectomia. Disponível em $<$ http:// pucrs.campus.br/ stainki/cirurgi/orquiectomia 2006.pdf.>. Acesso em: 31 maio 2014.

TRANQUILLI, W. J.; SKARDA, R. T. Técnicas de anestesia e analgesia local e regional: ruminantes e suínos. In: TRANQUILLI, W. J.; THURMON, J. C.; GRIMM, K.

A. Lumb\& Jones Anestesiologia e Analgesia Veterinária. 4. ed. São Paulo: Roca, 2013. p. 700.

TURNER, A. S.; McILWAITH, C. W. Técnicas cirúrgicas em animais de grande porte. São Paulo: Roca, 2002. p.

341. 